\title{
Tagging Atlantic bluefin tuna from a Mediterranean spawning ground using a purse seiner
}

Rouyer Tristan ${ }^{1,}{ }^{*}$, Bonhommeau Sylvain ${ }^{2}$, Giordano Nicolas ${ }^{3}$, Giordano François ${ }^{3}$, Ellul Saviour ${ }^{4}$, Ellul Giovanni ${ }^{4}$, Deguara Simeon ${ }^{5}$, Wendling Bertrand ${ }^{6}$, Bernard Serge ${ }^{7}$, Kerzerho Vincent ${ }^{7}$

${ }^{1}$ MARBEC, Univ. Montpellier, CNRS, Ifremer, IRD, Sète, France

2 IFREMER DOI, Rue Jean Bertho, 97822, Le Port, La Réunion, France

${ }^{3}$ Armement « Saint Sophie François II \& III », SARL SSF, 15 Quai d'Alger, 34200 Sète, France

${ }^{4}$ MFF Ltd, Hangar, Triq it - Trunciera, Marsaxlokk MXK 1522, Malta

${ }^{5}$ AquaBioTech Group, Central Complex Naggar Street - Targa Gap, Mosta MST 1761, Malta

${ }^{6}$ SATHOAN, 28, Promenade J.B. Marty, 34200 Sète, France

7 LIRMM, Univ. Montpellier, CNRS, Montpellier, France

* Corresponding author : Tristan Rouyer, email address : tristan.rouyer@ifremer.fr

\begin{abstract}
:
Atlantic bluefin tuna, Thunnus thynnus, is as an emblematic and commercially valuable large pelagic species. In the past ten years, the purse seine fishery in the Mediterranean represents more than $50 \%$ of the catch. Nowadays, purse seines target large fish and operate during the spawning season in the spawning grounds. Electronic tagging has shed a considerable amount of light on the ecology and behaviour of bluefin tuna over the past twenty years. However, such technique has rarely been applied on large bluefin tunas caught by the Mediterranean purse seine fishery despite its major importance. The logistical constraints related to this specific fishery, combined with the timing of migration of the fish and the requirements related to the handling of big fish have made adequate tagging from purse seines complex. Here we detail such an operation, designed to bridge the knowledge gap on the migratory behaviour of tunas targeted by the purse seine fishery. Three large bluefin tunas from the same school were tagged during the fishing operation of a French purse seine, resulting in a different migration pattern than previous deployments. The fish were tagged onboard in less than 2 min and efficiently, avoiding any subsequent mortality. These results contrast with those from tagging operations carried out in the Northwest Mediterranean, which underlies the importance of tagging operations from purse seines to obtain unbiased description of the movements of the eastern Atlantic bluefin tuna stock in the context of its management.
\end{abstract}




\section{Highlights}

- Tagging from purse seiners, the main fishery for bluefin tuna, is central to grasp its migrations. protocol to handle large bluefin tunas and enable tagging in good condition from purse seines is described. - Three large bluefin tunas were tagged onboard purse seiners from a spawning ground. The tracks were compared to tracks obtained previously from fish tagged in the Gulf of Lions with a smiliar method. - The fish from the Gulf of Lions displayed different migration patterns.

Keywords : Large Atlantic bluefin tuna, Eastern Atlantic and Mediterranean stock, Electronic tagging, Purse seine Migrations 


\section{1.INTRODUCTION}

43 Atlantic Bluefin Tuna (Thunnus thynnus, thereafter referred as BFT) is an emblematic species, whose

44 individuals can migrate across the Atlantic Ocean (Block et al., 2001; Fromentin and Powers, 2005;

45 Rooker et al., 2007). BFT is currently managed as two-stocks, Western and Eastern, by the 46 International Commission for the Conservation of Atlantic Tunas (ICCAT), but the two stocks display a 47 substantial amount of mixing (Puncher et al., 2018). The Eastern stock is much larger than the 48 Western one and Eastern catches represent about $90 \%$ of the total catch (ICCAT 2018 - task I). After a 49 complex history of over-exploitation, successive stock assessments since 2008 have shown that the 50 Eastern stock was recovering and increasing quotas were adopted (ICCAT, 2017). In 2017, the TAC 51 for the Eastern stock was set to be 28000 tons in 2018, 32000 tons in 2019 and 36000 tons by 2020.

53 The Eastern stock is exploited by 25 countries and 11 different types of gears. Most of the catch, $66 \%$ 54 in 2017, is made in the Mediterranean and is largely dominated by the purse seiners. Purse seine 55 catches represent more than $90 \%$ of the Mediterranean catches and have been representing more 56 than $50 \%$ of the overall Eastern stock catches over the past ten years (ICCAT 2018 - task I). They 57 operate during a reduced season in space and time, mostly during June and concentrate on the 58 spawning aggregations in the Balearic Islands, around Sicily and Malta, further south to Tunisia and 59 off Turkey in the East, Libyan waters being now unexploited. This fishery has been managed by strict 60 control measures since the enforcement of the Recovery Plan in the mid 2000s (ICCAT, 2017). The

61 Croatian purse seiners in the Adriatic differ from the other purse seiners as they exploit substantially 62 smaller fish (<4 year-old). Over the past ten years, the largest purse seiner catch has been France, 63 followed by Tunisia and Spain, representing $25 \%, 17 \%$ and $14 \%$ of the purse seine catch, 64 respectively. The BFT caught by the purse seine fishery is predominantly transferred to farms, where 65 the fish are caged and fattened until harvested. 
67 Since the late 1990s, electronic tagging has shed a considerable amount of light on the ecology of

68 BFT (Block et al., 2005; Fromentin and Lopuszanski, 2014; Teo et al., 2007). Electronic tags log

69 temperature, pressure and light and transmit this information via the Argos satellite system after a pre-

70 defined duration before release, often set between a few months and one year. This data allows

71 scientists to reconstruct the trajectory of the tagged fish in time and space. A large number of tags

72 have been deployed on BFT since this technique existed, covering various fleets and parts of the

73 species' life cycle, with the aim of describing as accurately as possible its migratory routes and

74 understanding the variability of these migrations (Abascal et al., 2016; Aranda et al., 2013; Arregui et

75 al., 2018; Cermeño et al., 2015; Fromentin and Lopuszanski, 2014; Galuardi et al., 2010; Galuardi and

76 Lutcavage, 2012). Tagging data are useful for management (Hays et al., 2019) and ICCAT has its own

77 tagging program coordinated by the Atlantic-Wide Research Program for Bluefin Tuna (GBYP). The

78 tracks obtained by tags deployed on BFT are used by the ICCAT Standing Committee on Research

79 and Statistics (SCRS) working group not only to improve the understanding on the ecology of the

80 species, but also to calibrate spatially explicit models, for instance in the context of the Management

81 Strategy Evaluation process (ICCAT MSE). Since the start of the use of this technique, and owing to a

82 larger research effort, substantially more tags have been deployed in the Western Atlantic than in the

83 Eastern Atlantic and Mediterranean. This uneven tagging effort is the opposite to the catch intensity as

84 the Western area only weighs about a tenth of the total catch.

85

86 Tagging BFT is not a trivial operation, specifically when the individual is large (e.g. > 70kg), as it 87 requires a skilled crew, suitable boat and material to catch and appropriately handle these animals for 88 tagging purpose (Rouyer et al., 2019). This constraints the ability of scientists to realize large-scale 89 deployments of tags on large BFT and requires specific logistics. Rod and reel (recreative or 90 professionnal) and traps are fishing gears that can provide fruitful opportunities for tagging BFT from 91 the eastern stock. However this still leaves a deficiency of tagging in the main fishing segment, i. e. 92 purse seined fish. Attempts for tagging purse seined BFT were made in the US coast (Wilson et al., 
93 2005), but tagging large fish from a purse seiner on the Mediterranean spawning grounds, the main

94 and key fishing segment of the eastern stock, has not been covered by tagging activities carried out by

95 the international scientific community.

96

97 The migratory behaviour of BFT is at the essence of the purse seine fishery, as it benefits from the 98 spawning behaviour of BFT, which aggregates for spawning in specific areas over a short amount of 99 time, typically mid-May to mid-July. In the northwestern Mediterranean BFT has been shown to display 100 strong residency (Cermeño et al., 2015; Fromentin and Lopuszanski, 2014), whereas Atlantic 101 individuals typically migrate within the Mediterranean in early spring and depart in July-August, often 102 seen as catches by the Morrocan and Portuguese traps (Fromentin and Powers, 2005; Rooker et al., 103 2007). Catches of purse seiners are composed by fish gathering in the spawning grounds in the 104 Mediterranean. Understanding the migrations routes of the BFT targeted by the purse seiners is 105 therefore of importance for the fishery and the conservation of the species, specifically to assess the 106 relative importance of BFT exiting the Mediterranean after spawning.

108 Here we describe a tagging operation designed as a first step to address these aspects. After previous 109 work using farming cages to set-up a protocol to efficiently tag BFT (Rouyer et al., 2019), an attempt 110 was made to transfer the protocol to a purse seiner during the 2018 fishing season to assess the 111 feasibility of such an operation on larger fish. The French purse seiners operate in two main fishing 112 grounds, the Balearic Islands and Malta, which are both well documented spawning grounds in the 113 Mediterranean. Two French purse seiner operating off Malta were used for the operation. The tracks 114 obtained from the tagged BFT are then compared to tracks obtained from tagging operations in the 115 Gulf of Lions (french Mediterranean), which target a different component of the population in terms of 116 age and behaviour. As tag data serve as input for connectivity/migration matrices used in spatially 117 explicit models, it is critical to collect information about the migration patterns from large individuals 118 targeted by purse seiners in the Mediterranean Sea. 
121 As tagging from a purse seiner involves complex logistics, the protocol has first been set-up in 122 cooperation with a Maltese fattening farm, MFF Ltd and has been described in Rouyer et al., 2019. 123 Tagging from a cage allowed to remove important constraints, such as the variability of the 124 meteorological conditions and the availability of fish, but also allowed to operate on fish with a lower 125 stress level as they are used to be held in a confined space. The following sections describe the 126 transposition of this protocol to a purse seiner.

\section{2.1.Purse seine set}

131 The French purse seine fishery operates mostly south of the Balearic Islands and south of Malta. The 132 purse seiner vessels that participated in this operation were the Saint Sophie François II (SSFII, 133 ICCAT serial number ATEUFRA00064) and the Saint Sophie François III (SSFIII, ICCAT serial number 134 ATEUFRA00065). The tagging team embarked on the purse seiner SSFIII from the harbour of 135 Birzebugga (Malta), on the $19^{\text {th }}$ of June 2018 , to rejoin the other vessels scouting the waters south of 136 Malta in search of BFT schools. The period was chosen late enough to avoid the bulk of the fishing 137 season associated with a higher probability of recapture, but early enough so that the post-spawning 138 migration was not at its highest and suitable meteorological conditions could be met. Flat sea and 139 sunny clear sky not only facilitate the operation, but also ensure that the fish remain as calm as 140 possible during the operation and would accept to be fed inside the purse seine for the tagging 141 operation. Such conditions were met the next day, on the $20^{\text {th }}$ of June 2018 (Fig. 1). A school detected 142 in the early morning was captured by SSFII. A transfer cage was organised to transfer the fish the next 143 day, which left the whole day for the tagging trials. Dinghies were deployed around the purse seine to 144 maintain it opened until the transfer cage arrived. 
147 2.2.Personnel and equipment

149 The purse-seiner SSFIII worked with his sistership SSFII and both crews, 13 people each, are 150 combined during the fishing and subsequent caging operations. Both ships have large decks and are 151 equipped with cranes. A piece of synthetic turf and a thick mattress were laid onto the free deck space, 152 so that the fish could be positioned appropriately for the tagging operation without hurting its lateral 153 line (Fig. 2). The location on the deck was also chosen so that the head of the fish could easily be 154 accessed by a sea water pump to supply the fish with oxygen while being held out of the water. One 155 crane was equipped with a stretcher specifically designed for such an operation, made of smooth 156 material to avoid scraping the fish skin and punctured with holes to let the water through. The stretcher 157 opening was equipped with a chain so that the fish could easily be maneuvered into it, whereas its 158 other end was closed with a rope, so that the fish would be held on the stretcher while being 159 maneuvered in the water and lifted onto the deck. The rope was designed to be easy to remove once 160 the fish needed to be released back into the sea. One crew member was tasked with operating the 161 handline. Two scientists were assigned the task to deploy the tags. One scientist was tasked with 162 covering the eyes and maintaining the water pipe into the mouth of the tuna and another one with 163 measuring the fish (curved forked length). Two crew members were tasked with removing the hook 164 with as much care as possible to avoid injuries. Three divers helped to maneuver the fish into the 165 stretcher placed into the water. One crew member operated the crane with the stretcher to move the 166 fish on the deck and in and out of the water as quickly and smoothly as possible. The ICCAT Regional 167 Observers on each of the fishing boat were present during the whole operation. 
172 Wildlife Computers' minipats were used for the deployments. They were programmed to remain

173 attached on the fish over the course of one year. The tether was $15 \mathrm{~cm}$ long and equipped with a large

174 Domeier anchor. A second anchor was added to reduce the lateral movements of the tag that could 175 hurt the fish and reduce deployment times (Fromentin and Lopuszanski, 2014). The main anchor of 176 the tags was inserted onto the base of the second dorsal fin. This location enables the anchor to get 177 tangled into hard bones, which increases the probability of long retention times (Cort et al., 2010). The 178 second anchor was directly inserted into the flesh. Chlorhexidine was used to treat all the material 179 before deployments.

181 The fish caught in the purse seine was fed with frozen sardine in order to induce feeding behaviour. A 182 long handline was prepared with hooks used by maltese longliners. A buoy was attached to the 183 mainline to help keeping the tuna at the surface. The hook was baited with frozen sardine and the line 184 was deployed in the purse seine. The purse seine was deployed to about $500 \mathrm{~m}$ long and the fishing 185 boat was far from the center of the seine. Thus, the handline was deployed using a small boat placed 186 into the purse seine while baiting with frozen sardine, which concentrated the tunas and induced 187 feeding behaviour. The line was left sinking a few seconds and was towed back towards the purse 188 seiner. Once a tuna took the bait, the fish was towed back by the fishermen as quickly and smoothly 189 as possible to avoid exhaustion of the fish or to break the line. The school caught by the purse seiner 190 was composed of large fish, whose acceleration when taking the bait was so intense that the line often 191 broke. Once the fish was close enough to the purse seiner, the stretcher was deployed and the divers 192 maneuvered the fish into it. The stretcher was then lifted onto the mattress on the deck, where the 193 eyes of the tuna were immediately covered with a wet cloth and the water pipe inserted into its mouth. 194 While the hook was being removed, the tag was deployed onto the fish. The stretcher was then hauled 195 back into the water, outside of the purse seine, the rope of the stretcher opening was undone and the 196 fish was released. 
199 2.4.Comparison to tracks obtained from the Gulf of Lions

200

201 A dataset of 44 tracks obtained from deployments on BFT in the Gulf of Lions by a recreative rod and 202 reel fishery was used to compare to the tracks obtained from the present tagging operation with purse 203 seiners. This dataset was acquired through deployments made between 2007 and 2015 in 204 cooperation with recreational fishermen, off Marseille, after the spawning season, from August through 205 to November (Fig. 1). Full details about the methodology of the deployments are available in 206 (Fromentin and Lopuszanski, 2014). The tracks from the dataset were simply plotted next to the tracks 207 obtained from the present operation to highlight differences in their dynamics. 
211 3.1.Tagging operation

212

213 About 15 BFT were hooked on the $20^{\text {th }}$ of June 2018 . The handlines prepared were just about strong 214 enough to handle the large animals but most of the lines broke, the crimps used to tie the line slipped 215 and/or the hooks were bent open. Three BFT of 226 (BFT1), 189 (BFT2) and $206 \mathrm{~cm}$ (BFT3) straight 216 fork length were caught at $11 \mathrm{~h} 30,14 \mathrm{~h} 30$ and $15 \mathrm{~h} 30$ respectively. The three fish did not fight more than

21715 minutes each time and were towed smoothly towards the divers who could maneuver it into the 218 stretcher. Once a fish was hauled onto the deck, less than 2 minutes were needed to intubate it, cover 219 his eyes with a soft and wet cloth and remove the hook from its mouth as carefully as possible. The 220 fish was then measured and tagged before being released into the water. No tagging-induced mortality 221 was observed.

222

223

\section{3.2.Tracks}

225

226 The retention times were 72 days, 62 days and 32 days for BFT1-3 respectively (Table 1). No 227 premature release was observed. Tags either indicated that the release pin broke or were recaptured.

228 BFT-2 appeared to have been recaptured by a fisherman in the Alboran sea as the tag moved onshore 229 following a straight line after it popped-up (Fig. 3). No tag was physically recovered. The GPE3 state230 space model algorithm from Wildlife computers was used to estimate the geolocation of the fish from 231 the tag data. BFT1 and BFT3 showed comparable dynamics as both fish reached the Alboran Sea in 232 about a month. They both went west of Sicily and south of Sardinia and via the Balearic Islands. BFT1 233 seemed to have passed more northern than BFT3 as it went via the island of Menorca before going 
234 more south passing Majorca and south of Ibiza, whereas BFT3 went more directly south of Ibiza,

235 around where another major fishing ground is located. BFT1 reached the straight of Gilbraltar three to

236 four days before BFT3. Whereas BFT3 was recaptured at this point, BFT1 exited the Mediterranean

237 and followed the continental shelf along the Portuguese and Spanish coasts up to the Bay of Biscay

238 where it stayed for about three weeks from late July to the middle of August 2018. BFT1 then

239 continued its route towards Ireland where the release pin broke. BFT2 contrasted with these two

240 routes. The fish did not attempt any large scale movement, so whilst BFT1 and BFT3 were setting off

241 for the Atlantic, BFT2 went south into Libyan waters where it stayed two months until the tag popped-

242 off in late August.

\section{3.3.Comparison to the Gulf of Lions dataset}

247 The 44 tracks from tagging operations realized in the Gulf of Lions between 2007 and 2015 were 248 plotted next to the tracks obtained from the purse seiner deployment reported here. This dataset 249 spans fish of various sizes (up to $237 \mathrm{~cm}$ ) comparable to the ones tagged from the purse seiner and 250 exhibit times at liberty of up to a year. The fish were tagged after the spawning season, from late July 251 to November off the city of Marseille. Not one single fish from this dataset made its way out of the 252 Mediterranean. The closest attempt was a fish that just crossed the Straits of Gibraltar and 253 immediately after headed back to the Gulf of Lions, close to where it was tagged. This contrasted with 254 the present results that displayed one fish exiting the Mediterranean an another one that seemed to be 255 on its way to do so before it was captured. 
258 The operation described here presents a successful tagging attempt of large BFT in one of their

259 Mediterranean spawning ground, during the spawning season. The tags deployed during this 260 operation document the migration of individuals targeted by the largest fishery segment operating on

261 BFT. A past operation using purse seiners in the US coast used harpoons to tag the animals (Wilson et 262 al., 2005). Our results show that tagging large individuals from the spawning grounds on the deck of 263 purse seiners is possible. The tracks obtained from these deployments contrast with the results 264 obtained by tagging operations performed in other areas, periods and gears. This manuscript 265 underlines the importance of such operations to fully grasp the migratory behaviour of BFT in the 266 Mediterranean.

268 Results obtained from other tagging operations in the northwest Mediterranean have displayed 269 relatively strong fidelity to the Mediterranean (Cermeño et al., 2015; Fromentin and Lopuszanski, 270 2014). In contrast, the results obtained in the present manuscript tend to suggest migrations outside of 271 the Mediterranean, but this will have to be confirmed by more tracks. These different patterns can be 272 explained by different factors, one being the period of the operation. Post-spawning tagging operations 273 are often favoured as tagging before the purse seine fishing season is increasing the likelihood of 274 early recaptures that reduces the probability of long tracks. In addition, a large number of tagging 275 operations in the Mediterranean are carried out in cooperation with recreative fisheries, which also 276 operate more easily in summer (Cermeño et al., 2015; Fromentin and Lopuszanski, 2014; Stokesbury 277 et al., 2007). This induces a bias on the migratory patterns captured by the tags deployed, as tagging 278 BFT after the spawning season targets fish that did not migrate outside the Mediterranean, such as 279 BFT2. In addition, recreative fisheries operate nearer to shore than professional ones where large 280 schools are less frequent. The group dynamics captured is thus likely to be different compared to the 281 group dynamics of individuals from the spawning grounds, where large aggregation of fish are 
commonly encountered. Tags deployed from the spawning grounds and during the spawning season therefore target individuals likely to have a different behaviour than the fish targeted by recreative fisheries. One fish over the three released was recaptured, but not enough tags were deployed to strictly assess whether a larger amount of early recaptures happened than during other periods. Regarding deployment times, a salient aspect was the failure of the release system of the tag ("pinbreak") that impaired the retention times achieved by the tags deployed during the operation.

Given the right conditions and the right technique, tagging from a purse seiner can be an advantage in terms of logistics, as purse seiners often catch a very large amount of BFT in less than a day. The first attempt described in the present manuscript show that 3 fish could be tagged in less than an hour of cumulative time, although the technique presented has also a lot of room for improvement, as only three tunas were tagged when about 15 of them had actually been hooked. Compared to the operation carried out in fattening cages (Rouyer et al., 2019), decking the tunas from the purse seine proved to be much more complex. The main problematic aspect was the size and the strength of the

296 individuals captured that broke the handlines deployed. Improving the strength of the material used for 297 the handlines, shock-leader and hooks, should improve this aspect for future operations. Yet, the 298 technique still enabled the decking of a fish estimated to weigh $250 \mathrm{~kg}$ (BFT1) in less than $15 \mathrm{mn}$. The 299 rate at which the tunas were taking the baits suggested that 15 fish tagged during one day is not an unrealistic target given that the right meteorological conditions are met. Such large scale deployments repeated on different schools would provide a unique source of insights into BFT migratory behaviour. spawning grounds is an opportunity to draw a clearer picture of BFT migrations. Spawning grounds, 
308 2007). Tagging from such an area could therefore allow scientists to capture a large range of migratory

309 behaviours, which would draw a clearer picture of the relative importance between resident individuals

310 and individuals migrating outside of the Mediterranean. Our results illustrate this aspect, as it showed

311 that fish from the same school, and whose tagging conditions were as similar as possible, displayed

312 very different migratory patterns. The trajectory of BFT1 was consistent with observations of BFT

313 migrating to northern latitudes during the recent past years, as the fish went straight to Ireland after

314 spending some time in the Bay of Biscay. BFT3 seemed to also exit the Mediterranean, whereas BFT2

315 displayed a more residential behaviour in Libyan waters.

316

317 From a management point of view, and in the context of climate change, understanding the migratory

318 behaviour of BFT is of key importance. For instance, within ICCAT, the ongoing Management Strategy

319 Evaluation process uses spatially explicit model that requires migration rates between areas to

320 capture the movement of the stock. ICCAT therefore encourages tagging activities, as accurately

321 depicting migrations and exchange rates between areas from the major fisheries segments is of key

322 importance. The operation described here is thus an important step to enable the international

323 scientific community to move forward in that direction, providing information from the largest BFT

324 fishing segment. 


\section{ACKNOWLEDGEMENTS}

327 This research was part of the MERLIN-POPSTAR project funded by Ifremer. We thank our

328 colleagues from Ifremer/REM/RDT and RBE, CNRS, UM and IRD who provided insight and

329 expertise that greatly assisted the research. We thank MFF Ltd for letting us use their facilities

330 and the crew for their great skills and assistance. We also thank the crew of SSFII and SSFIII

331 for their skills and their help to make the operation possible. We also thank the EU (DG-

332 MARE), ICCAT GBYP and the French ministry department of marine fisheries and

333 artuaculture (DPMA) for their support in the administrative aspects of this operation. 
Abascal, F.J., Medina, A., De La Serna, J.M., Godoy, D., Aranda, G., 2016. Tracking bluefin tuna reproductive migration into the Mediterranean Sea with electronic pop-up satellite archival tags using two tagging procedures. Fish. Oceanogr. 25, 54-66. https://doi.org/10.1111/fog.12134

Aranda, G., Abascal, F.J., Varela, J.L., Medina, A., 2013. Spawning Behaviour and Post-Spawning Migration Patterns of Atlantic Bluefin Tuna (Thunnus thynnus) Ascertained from Satellite Archival Tags. PLOS ONE 8, e76445. https://doi.org/10.1371/journal.pone.0076445

Arregui, I., Galuardi, B., Goñi, N., Lam, C.H., Fraile, I., Santiago, J., Lutcavage, M., Arrizabalaga, H., 2018. Movements and geographic distribution of juvenile bluefin tuna in the Northeast Atlantic, described through internal and satellite archival tags. ICES J. Mar. Sci. 75, 1560-1572. https://doi.org/10.1093/icesjms/fsy056

Block, B.A., Dewar, H., Blackwell, S.B., Williams, T.D., Prince, E.D., Farwell, C.J., Boustany, A., Teo, S.L.H., Seitz, A., Walli, A., Fudge, D., 2001. Migratory Movements, Depth Preferences, and Thermal Biology of Atlantic Bluefin Tuna. Science 293, 1310-1314. https://doi.org/10.1126/science.1061197

Block, B.A., Teo, S.L.H., Walli, A., Boustany, A., Stokesbury, M.J.W., Farwell, C.J., Weng, K.C., Dewar, H., Williams, T.D., 2005. Electronic tagging and population structure of Atlantic bluefin tuna. Nature 434, 1121-1127.

Cermeño, P., Quílez-Badia, G., Ospina-Alvarez, A., Sainz-Trápaga, S., Boustany, A.M., Seitz, A.C., Tudela, S., Block, B.A., 2015. Electronic Tagging of Atlantic Bluefin Tuna (Thunnus thynnus, L.) Reveals Habitat Use and Behaviors in the Mediterranean Sea. PLOS ONE 10, e0116638. https://doi.org/10.1371/journal.pone.0116638

Cort, J.L., Abascal, F., Belda, E., Bello, G., Deflorio, M., Estruch, V., Godoy, D., Velasco, M., 2010. TAGGING MANUAL FOR THE ATLANTIC-WIDE RESEARCH PROGRAMME FOR BLUEFIN TUNA (ICCAT-GBYP). . INTRODUCTION 45. 
Fromentin, J.-M., Lopuszanski, D., 2014. Migration, residency, and homing of bluefin tuna in the western Mediterranean Sea. ICES J. Mar. Sci. J. Cons. fst157. https://doi.org/10.1093/icesjms/fst157

Fromentin, J.M., Powers, J.E., 2005. Atlantic bluefin tuna: population dynamics, ecology, fisheries and management. Fish Fish. 6, 281-306.

Galuardi, B., Lutcavage, M., 2012. Dispersal Routes and Habitat Utilization of Juvenile Atlantic Bluefin Tuna, Thunnus thynnus, Tracked with Mini PSAT and Archival Tags. PLOS ONE 7, e37829. https://doi.org/10.1371/journal.pone.0037829

Galuardi, B., Royer, F., Golet, W., Logan, J., Neilson, J., Lutcavage, M., 2010. Complex migration routes of Atlantic bluefin tuna (Thunnus thynnus) question current population structure paradigm. Can. J. Fish. Aquat. Sci. 67, 966-976. https://doi.org/10.1139/F10-033 Hays, G.C., Bailey, H., Bograd, S.J., Bowen, W.D., Campagna, C., Carmichael, R.H., Casale, P., Chiaradia, A., Costa, D.P., Cuevas, E., Nico de Bruyn, P.J., Dias, M.P., Duarte, C.M., Dunn, D.C., Dutton, P.H., Esteban, N., Friedlaender, A., Goetz, K.T., Godley, B.J., Halpin, P.N., Hamann, M., Hammerschlag, N., Harcourt, R., Harrison, A.-L., Hazen, E.L., Heupel, M.R., Hoyt, E., Humphries, N.E., Kot, C.Y., Lea, J.S.E., Marsh, H., Maxwell, S.M., McMahon, C.R., Notarbartolo di Sciara, G., Palacios, D.M., Phillips, R.A., Righton, D., Schofield, G., Seminoff, J.A., Simpfendorfer, C.A., Sims, D.W., Takahashi, A., Tetley, M.J., Thums, M., Trathan, P.N., Villegas-Amtmann, S., Wells, R.S., Whiting, S.D., Wildermann, N.E., Sequeira, A.M.M., 2019. Translating Marine Animal Tracking Data into Conservation Policy and Management. Trends Ecol. Evol. https://doi.org/10.1016/j.tree.2019.01.009

ICCAT, 2017. Report of the 2017 ICCAT bluefin stock assessment meeting. Col Vol Sci Pap ICCAT 74, 2372-2535.

Mather, F.J. (Frank J., Southeast Fisheries Science Center (U.S.), Mason, J.M., Jones, A.C. (Albert C., 1995. Historical document : life history and fisheries of Atlantic bluefin tuna. Miami, Fla. U.S. Dept. of Commerce, National Oceanic and Atmospheric Administration, National Marine 
Fisheries Service, [Southeast Fisheries Science Center ; Springfield, Va. : National Technical Information Service.

Puncher, G.N., Cariani, A., Maes, G.E., Houdt, J.V., Herten, K., Cannas, R., Rodriguez-Ezpeleta, N., Albaina, A., Estonba, A., Lutcavage, M., Hanke, A., Rooker, J., Franks, J.S., Quattro, J.M., Basilone, G., Fraile, I., Laconcha, U., Goñi, N., Kimoto, A., Macías, D., Alemany, F., Deguara, S., Zgozi, S.W., Garibaldi, F., Oray, I.K., Karakulak, F.S., Abid, N., Santos, M.N., Addis, P., Arrizabalaga, H., Tinti, F., 2018. Spatial dynamics and mixing of bluefin tuna in the Atlantic Ocean and Mediterranean Sea revealed using next-generation sequencing. Mol. Ecol. Resour. 18, 620-638. https://doi.org/10.1111/1755-0998.12764

Rooker, J.R., Bremer, J.R.A., Block, B.A., Dewar, H., Metrio, G. de, Corriero, A., Kraus, R.T., Prince, E.D., Rodríguez-Marín, E., Secor, D.H., 2007. Life History and Stock Structure of Atlantic Bluefin Tuna (Thunnus thynnus). Rev. Fish. Sci. 15, 265-310. https://doi.org/10.1080/10641260701484135

Rouyer, T., Bonhommeau, S., Giordano, N., Ellul, S., Ellul, G., Deguara, S., Wendling, B., Belhaj, M.M., Kerzerho, V., Bernard, S., 2019. Tagging Atlantic bluefin tuna from a farming cage: An attempt to reduce handling times for large scale deployments. Fish. Res. 211, 27-31. https://doi.org/10.1016/j.fishres.2018.10.025

Stokesbury, M.J.W., Cosgrove, R., Boustany, A., Browne, D., Teo, S.L.H., O’Dor, R.K., Block, B.A., 2007. Results of satellite tagging of Atlantic bluefin tuna, Thunnus thynnus, off the coast of Ireland, in: Almeida, P.R., Quintella, B.R., Costa, M.J., Moore, A. (Eds.), Developments in Fish Telemetry, Developments in Hydrobiology 195. Springer Netherlands, pp. 91-97.

Teo, S.L.H., Boustany, A., Dewar, H., Stokesbury, M.J.W., Weng, K.C., Beemer, S., Seitz, A.C., Farwell, C.J., Prince, E.D., Block, B.A., 2007. Annual migrations, diving behavior, and thermal biology of Atlantic bluefin tuna, Thunnus thynnus, on their Gulf of Mexico breeding grounds. Mar. Biol. 151, 1-18. https://doi.org/10.1007/s00227-006-0447-5 
Wilson, S.G., Lutcavage, M.E., Brill, R.W., Genovese, M.P., Cooper, A.B., Everly, A.W., 2005. Movements of bluefin tuna (Thunnus thynnus) in the northwestern Atlantic Ocean recorded by pop-up satellite archival tags. Mar. Biol. 146, 409-423. https://doi.org/10.1007/s00227-0041445-0 
335 TABLE

336

337 Table 1: Information about the three tags deployed.

\begin{tabular}{|l|c|c|c|}
\hline Tag & Straight fork length $(\mathrm{cm})$ & Time of tagging & Time at liberty (days) \\
\hline BFT1 & 226 & $11 \mathrm{~h} 30$ & 72 \\
\hline BFT2 & 189 & $14 \mathrm{~h} 30$ & 62 \\
\hline BFT3 & 206 & $15 \mathrm{~h} 30$ & 32 \\
\hline
\end{tabular}


339 FIGURE LEGENDS

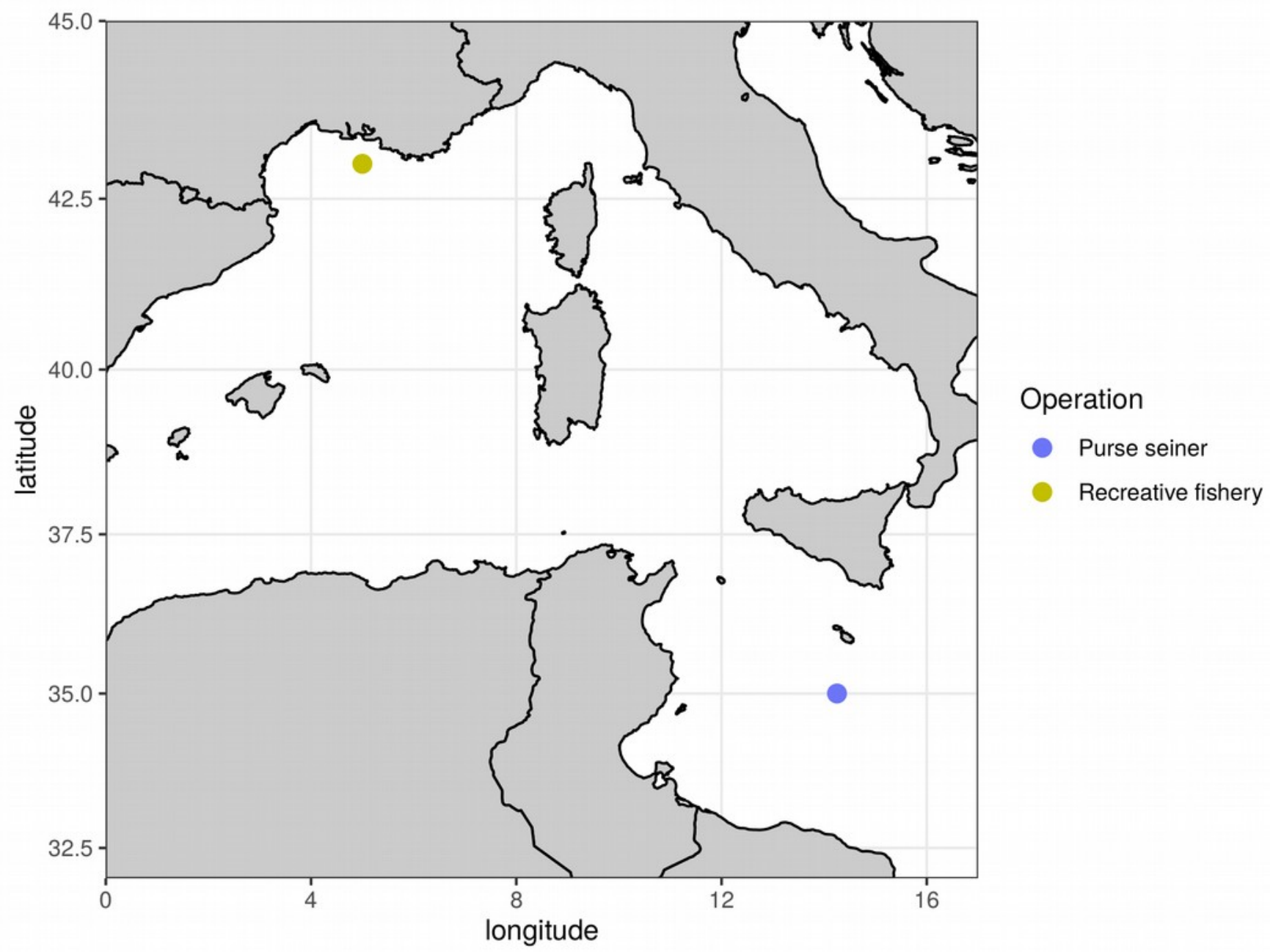

341 Figure 1: Location of purse seiner and recreative fishery tagging operations. 

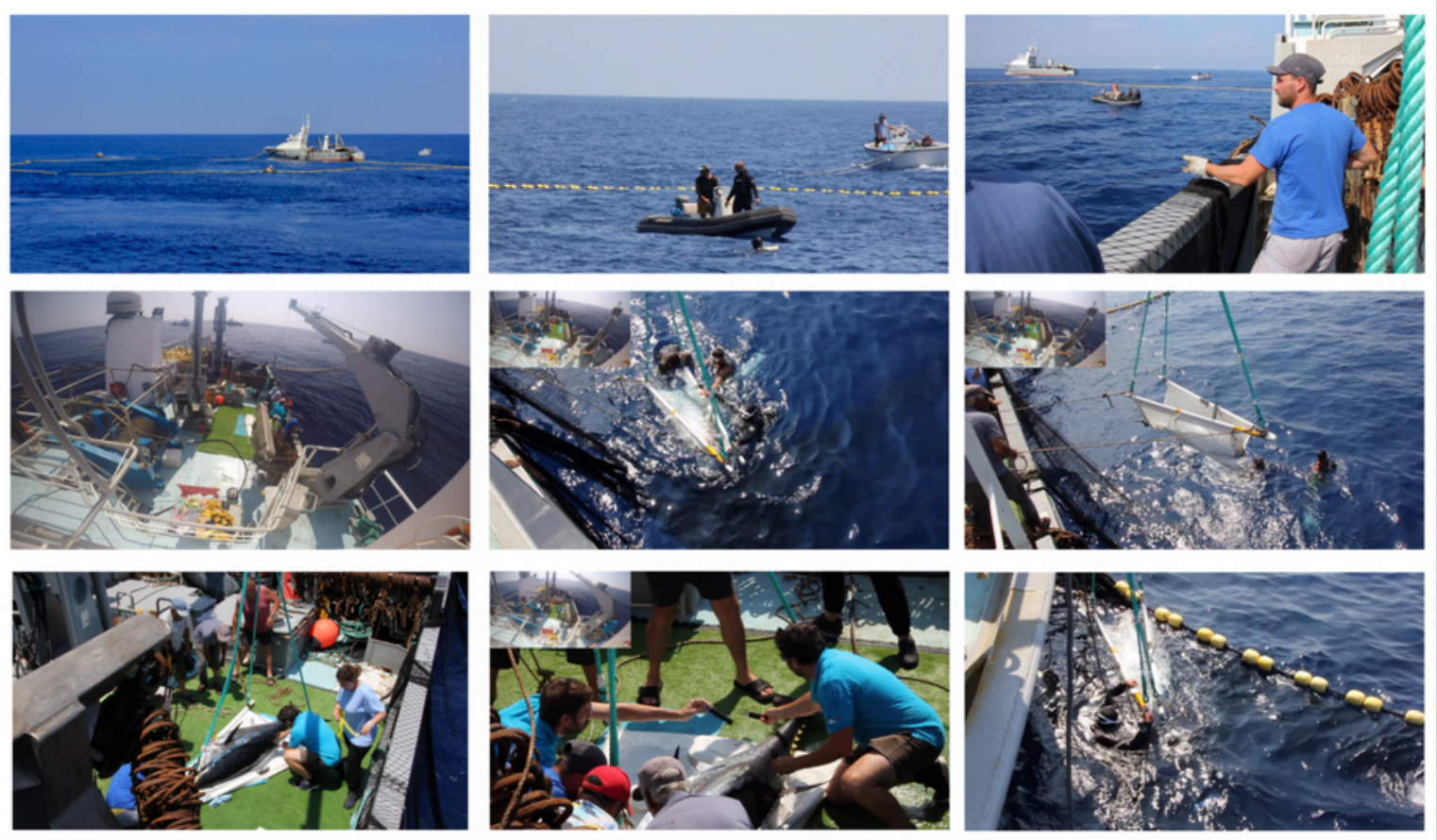

344 Figure 2: Main steps of the tagging operation. From top left to bottom right. A school of tunas

345 was captured by the purse seiner SSFII. The purse seine was maintained open while waiting

346 to transfer the fish into a cage. A dinghy was placed in the purse seine to deploy the baited

347 handline, which was left to sink a few seconds and then slowly towed from the vessel. Once a

348 tuna was hooked, it was towed in as fast and smoothly as possible. A clean space over the

349 deck was prepared with a mattress and a water pipe. Once the tuna was close enough to the

350 boat, three divers manoeuvered the fish inside a stretcher attached to a crane. The fish was

351 then hauled onto the deck and then tagged using a double anchorage. It was immediately 352 released outside of the purse seine. 


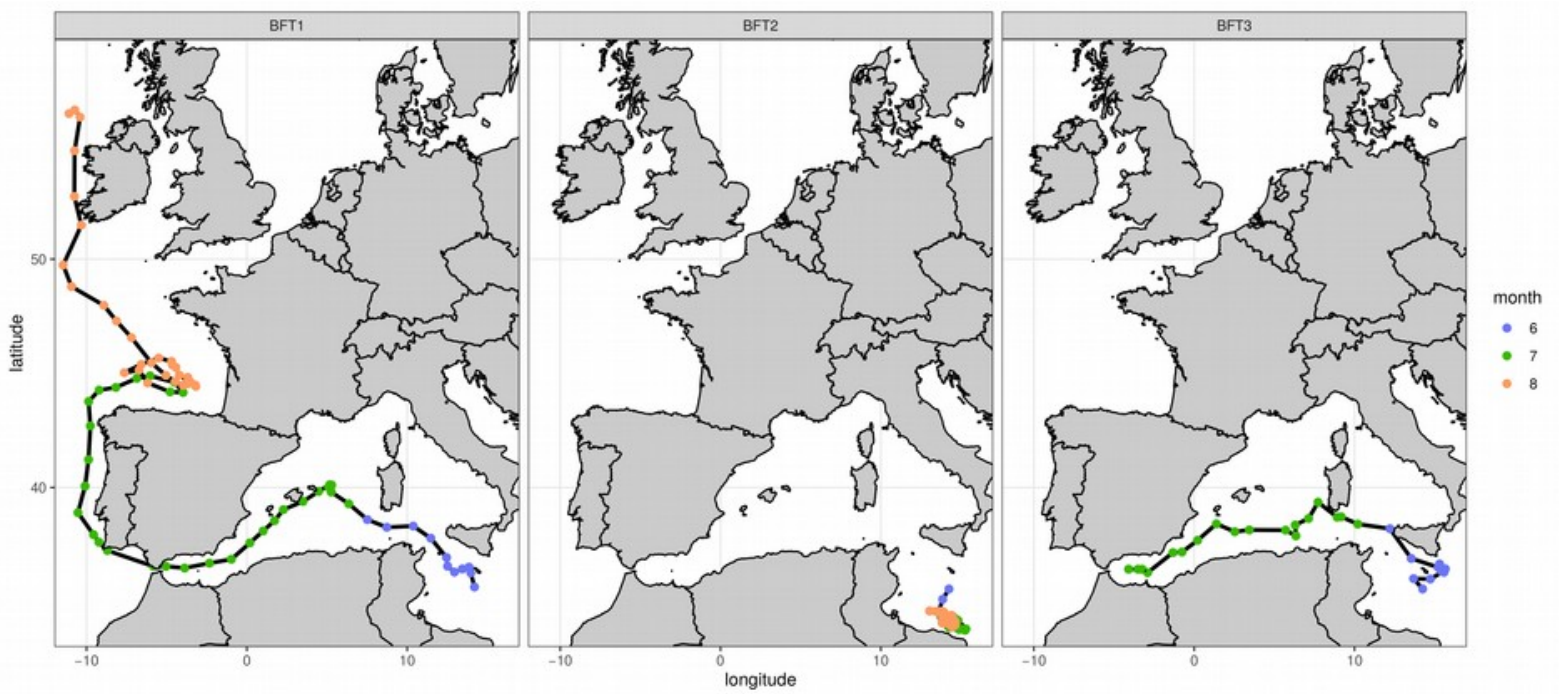

355 Figure 3: Tracks of the fish tagged during the operation obtained from Wildlife Computer's 356 GPE3 algorithm. 


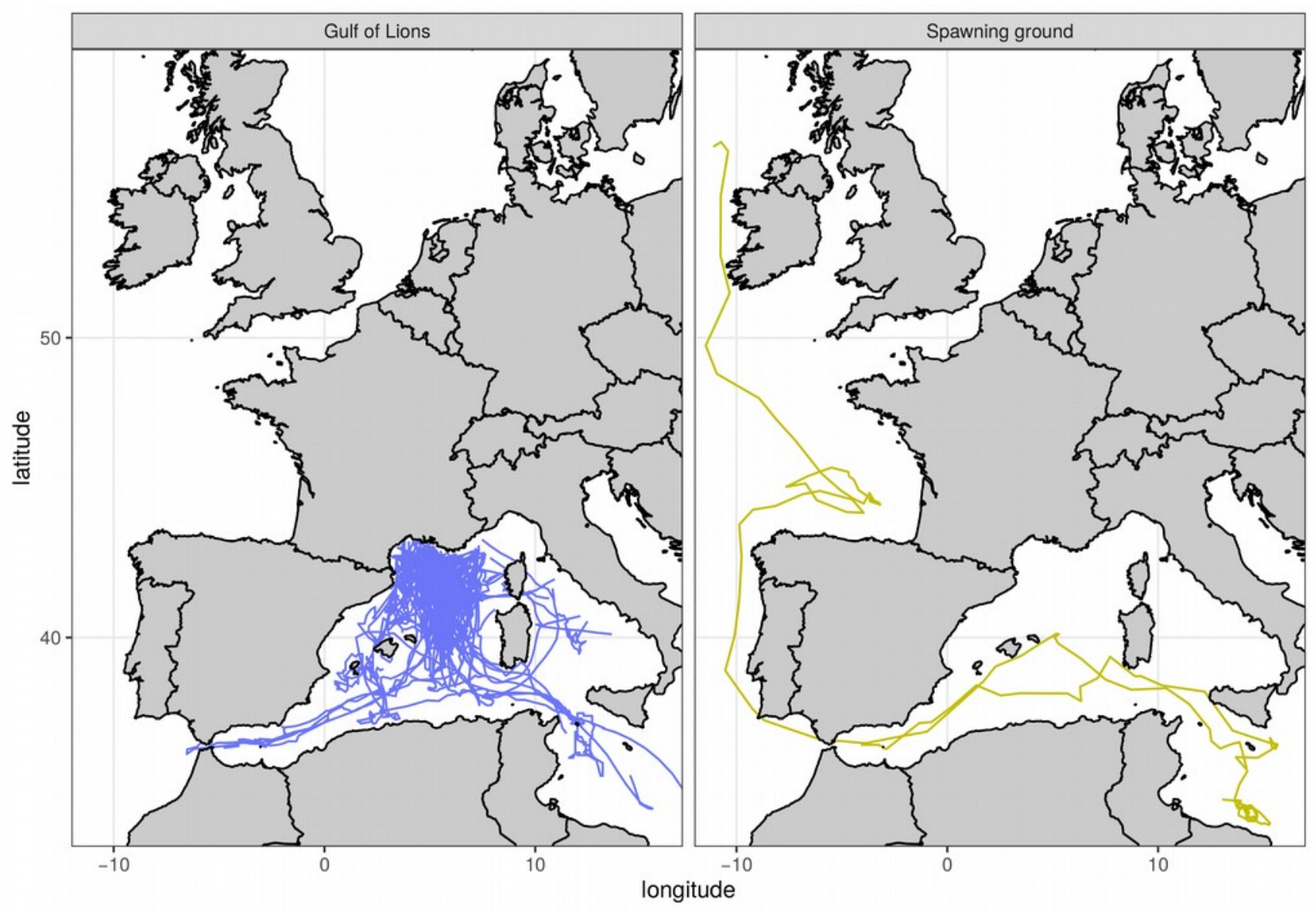

359 Figure 4: Comparison of the tracks obtained from the tagging operations in the Gulf of Lions 360 and from the Purse Seiner. 